\title{
Coulisses
}

Revue de théâtre

15 | Hiver 1997

Varia

Martine Meirieu, Se (re)connaître par le théâtre. Lyon, Chronique sociale, 1996

\section{Christian Pratoussy}

\section{(2) OpenEdition}

1 Journals

Édition électronique

URL : http://journals.openedition.org/coulisses/5219

DOI : $10.4000 /$ coulisses.5219

ISSN : 2546-9460

Éditeur

Presses universitaires de Franche-Comté

\section{Édition imprimée}

Date de publication : 1 janvier 1997

Pagination : 73

ISSN : 1150-594X

\section{Référence électronique}

Christian Pratoussy, "Martine Meirieu, Se (re)connaître par le théâtre. Lyon, Chronique sociale, 1996 »,

Coulisses [En ligne], 15 I Hiver 1997, mis en ligne le 26 avril 2019, consulté le 24 septembre 2020. URL : http://journals.openedition.org/coulisses/5219 ; DOI : https://doi.org/10.4000/coulisses.5219

Ce document a été généré automatiquement le 24 septembre 2020.

Coulisses 


\title{
Martine Meirieu, Se (re)connaître par le théâtre. Lyon, Chronique sociale, 1996
}

\author{
Christian Pratoussy
}

D'ordinaire, un livre-somme est lourd, épais. Celui de Martine Meirieu, un livre-somme justement, est, au contraire, léger. Ce qui ne l'empêche pas d'être grave. Martine Meirieu, à son tour pourrait-on dire, vient de publier un livre sur le théâtre. Mais ce n'est pas un livre de plus sur le théâtre. Ce serait plutôt sur un plus du théâtre. En l'occurrence, l'auteur, comédienne, intervenante auprès d'handicapés physiques ou mentaux, n'attend pas le nombre des pages et nous fait part de son expérience, mieux, de sa vie de théâtre.

Et son théâtre n'est pas seulement de l'expression dramatique: c'est un théâtre de citoyen. Et ce mot-là prend encore plus de sens quand on pense au public auprès duquel elle intervient, public, à l'accoutumée, exclu de la société. Le théâtre retrouve là certaines de ses lettres de noblesse, lettres qui, par parenthèse, n'arrivent pas toujours aujourd'hui à l'adresse indiquée. L'adresse principale du théâtre, ici, c'est l'éducation, que Martine Meirieu décline en une double problématique : une éducation aux droits des personnes est-elle possible ? L'éducation n'est-elle pas d'abord une éducation aux droits des personnes? Ce qui conduit l'ouvrage à être rythmé en trois temps, trois temps fondés sur trois déclarations, celle des droits de l'homme, celle des droits de l'enfant, celle des droits de la personne handicapée qui sont, quasi in extenso, présents dans le texte, et dont on n'a pas le droit de s'exonérer de la lecture. Mettant à l'épreuve l'adage agréant que rien n'est plus pratique qu'une bonne théorie, ces trois temps sont ainsi à la fois pensés, pratiqués, expérimentés (rappelons que le livre est sous-titré : "Outils pour l'école, la formation, l'éducation spécialisée »), avec tel ou tel groupe d'enfants et d'adultes réguliers ou irréguliers, pour parler comme Delcroy.

3 La question que nous pourrions être amenés à nous poser est celle de la réaction, en tant que femme régulière, de Martine Meirieu. En effet, la personne handicapée gêne, dérange notre régularité. Au théâtre, lorsque cette personne joue, la gêne du spectateur 
se transforme en un certain doute, une sorte de doute noble et fondateur de l'humanité. Dans le quotidien des ateliers, comment fait-elle? Elle ne répond pas à cette question. Par contre, elle nous dit bien comment elle est. Une partie courte, mais très importante, intitulée «Histoire de Martine " (succédant à d'autres histoires, celle de Simon, de Louise, de Sébastien, de Lucile, tous psychotiques), donne tout sa légitimité au livre : on n'intervient pas dans ce milieu sans être au clair avec soi-même, tout du moins sans essayer de l'être. Il est d'ailleurs regrettable que Martine Meirieu craigne que certains prennent cette partie pour du «narcissisme forcené ». Bien au contraire, ces lignes-là sont capitales pour la cohérence de l'ouvrage.

"Enfant déjà je détestais la guerre ». D'autres, depuis longtemps, se couchaient de bonne heure. Si les deux attitudes ne sont pas inconciliables, la première, celle de Martine Meirieu, paraît plus profitable à l'Autre. Ces portraits d'handicapés en artistes, se situant «entre le champ pédagogique et le champ poétique, la didactique et le récit", font un livre léger par le format, mais d'une gravité qui serait presque insoutenable. 